\title{
The Investment of Information Security and Real Option
}

\author{
DongWook $\mathrm{Cho}^{+} \cdot$ Jongln $\mathrm{Lim}^{+\dagger}$
}

\begin{abstract}
Although many companies acknowledge the necessity of investment of information security, it is difficult to grasp a tangible effect and to calculate a scale of damage from the security incident. Consequently, companies are under the reality that it is not easy to make an investment decision for information security and to calculate the investment scale.

For the investment decision making, although there are several traditional techniques of investment analysis, the investment of information security, comparing to other tangible assets, has limitations in using traditional techniques due to the highly uncertain investment effects.

In this study, the traditional technique of investment analysis will be described, and the application method of analytic technique for Real Option, which is developed from the evaluation technique of highly uncertain financial futures and options, will be suggested.
\end{abstract}

\section{Keywords : Information Security Investment, Real Option}

\section{정보보호투자와 실물옵션}

\author{
조 동 욱 $^{+}$임 종 인 $^{++}$
}

\begin{abstract}
요 약
다수의 기업은 정보보호투자에 대한 필요성은 인식하고 있으나, 정보보호 투자로 인한 효과가 가시적으로 파악하기 힘들고, 침해사고로 인 한 피해규모 또한 산정하기 매우 힘들다. 그렇기 때문에 기업은 정보보호에 관한 투자의사결정을 하기도 쉽지 않고 투자규모 또한 산정하기 쉽 지 않은 실정이다. 물론 기업의 투자의사결정을 위한 전통적인 투자기법들은 많지만, 정보보호투자는 다른 실물자산에 대한 투자에 비하여 투 자효과의 불확실성이 매우 높기 때문에 전통적인 투자분석 기법으로는 한계를 가지고 있다. 본 연구에서는 기업이 투자 의사결정을 함에 있어 서 전통적으로 사용한 투자분석기법들에 대해 기술하고, 미래에 대한 불확실성이 큰 금융 선물(先物),옵션(Option)의 평가기법에서 발전한 실물 옵션(Real Option) 분석기법을 정보보호투자 분석에 활용하는 방법을 제시하고자 한다.
\end{abstract}

키워드 : 정보보호투자, 실물옵션

\section{1. 서 론}

최근보도자료(2012년3월)를 통한 방송통신위원회(www. kcc.or.kr)의 2011년 정보보호 실태조사 결과 발표에 의하면, 국내기업 중 종사자수 5 인 이상의 네트워크 구축 사업체 5,000 개를 조사한 결과 $62.6 \%$ (정보화 투자 대비 정보보호 투자 비율 $1 \%$ 미만 기업 포함 시 $82.9 \%$ )의 사업체가 정보 보호에 투자를 하지 않고 있으며, 정보보호 투자를 하지 않 는 이유에 대해 $53.9 \%$ 가 '필요성을 못 느끼기 때문'이라고 답하고 있으며, 침해사고 대응을 위한 별다른 활동을 수행 하지 않는 기업이 2010 년 대비 $12.0 \% \mathrm{p}$ 증가한 $55.9 \%$ 에 달

\footnotetext{
† 정 회 원: 고려대학교 정보보호학과 석사과정

†† 정 회 원 : 고려대학교 자연과학대학 정교수

돈문접수: 2012년 8월 16일

심사완료 : 2012년 9월 11일

* Corresponding Author: JongIn Lim(jilim@korea.ac.kr)
}

한다[1]. 이처럼 여전히 많은 기업이 정보보호를 불필요한 비용으로 인식하고 있다. 정보보호에 대한 투자가 매출증대 나 비용절감을 통하여 기업의 이익극대화에 기여할지에 대 하여 구체적인 확신이 없기 때문이다.

기업은 투자 의사결정에 있어서 투입대비 얻는 효과가 보 다 긍정적이어야 투자의사결정을 할 것이며, 이를 통하여 기업은 기업가치 극대화를 통하여 기업의 생명을 지속적으 로 영위해 나아갈 수 있을 것이다. 기업차원에서 정보보호 투자에 대한 필요성은 인식하고 있으나 기업의 정보보호투 자는 투자로 인한 효과가 가시적으로 파악하기 힘들고, 침 해사고로 인한 피해규모 또한 산정하기 매우 힘들다. 그렇 기 때문에 기업은 정보보호 투자의사결정을 하기도 쉽지 않 고, 투자규모 또한 산정하기 매우 어려운 실정이다.

그러나, 기업은 분명히 어떠한 투자의사결정을 하기 전에 그 투자의 효과를 산정하기 위해 다양한 투자 효과분석을 시 
도할 것이며, 이러한 분석으로 인한 결과가 의미있게 도출되 어서, 기업 가치 극대화에 기여한다라는 결론이 도출될 경우 에 투자 의사결정을 할 것이다. 이에 본 연구는 정보보호 및 일반 투자가치분석의 선행연구 성격인 연간 예상손실액 (ALE, Annual Loss Expectancy)을 통하여 정보보호투자관 련 비용, 편익을 파악하고 전통적 투자가치 평가방법인 순현 재가치(NPV, Net Present Value)법, 내부수익률(IRR, Internal Rate of Return on Investment)법 및 몬테카를로 시 뮬레이션에 대해 설명하고, 실물옵션의 이론적 기초가 되는 금융옵션의 블랙-숄즈모형 및 이항옵션가격결정모형에 대해 기술한 뒤에 실물옵션으로서의 정보보호 투자분석시 고려할 중요 사항에 대해 기술할 것이다. 마지막으로 사례연구를 통 하여 정보보호투자 분석에 있어서 실물옵션의 유용성을 제시 함으로써 정보보호 투자 활성화에 기여하고자 한다.

\section{2. 이론적 배경 및 선행 연구}

\section{1 예상손실액(ALE, Annual Loss Expectancy)}

2005 CSI/FBI Computer Crime and Security Survey 에 따르면 많은 기업들이 정보보호 부문의 투자의사 결정에 있 어서 많은 경제학적 분석방법을 적용하기 시작했다고 한다. 예를 들자면 아래와 같은 방법들을 들 수 있겠다[22].

- Return on Security Investment (ROSI),

- 순현재가치법

- 내부 수익률법

정보보호 투자에 대한 수익은 투자비용에 기초한 정량적 또는 정성적 편익과 관계되어 있으며, 경제적 관점에서 보 면 투자비용을 상회하는 편익이 매우 중요한 의사결정 요소 일 것이다. 이것을 수식으로 표현하자면 아래와 같이 표현 할 수 있을 것이다.

$$
\frac{\text { 순편익 }(=\text { 총편익 }- \text { 투자비용 })}{\text { 투자비용 }}
$$

회사가 투자하는 것은 주로 고정자산(Fixed Assets)이 며, 이러한 자산은 상대적으로 쉽게 수치화된 데이터를 산 출해 낼 수 있을 것이다. 그러나 문제는 편익을 수치화 하 는 것이다. 예를 들면 방화벽(Firewall)과 침입탐지시스템 (IDS)은 가시적인 수익을 창출해 내지 않는다. 이러한 어 려움이 정보보호 투자에 대한 저해요인으로 작용하는 것이 다. 침해사고 위험을 측정하는 초기의 연구는 $\mathrm{ALE}$ (Annual Loss Expectancy) 모델이다. 이 모델은 (예상된 침해 사고 확률 $\times$ 사고의 충격)을 곱하는 계량적 모델이다.

즉 ALE는 두 가지 요소를 고려한다. 침해사고로 인한 손 실과 침해사고가 일어날 가능성(확률)이 그것이다.

ALE는 확률과 기업의 주어진 년도에 예상되는 실제 손 실의 수치를 결합하는 형태이다[3].

$$
A L E=\sum_{t=1}^{n} I\left(O_{i}\right) F_{i}
$$

$\left\{O_{1}, O_{2}, \cdots O_{n}\right\}$ 은 위해를 끼칠 수 있는 $\mathrm{n}$ 개의 보안 사고 들의 집합이고, $I\left(O_{i}\right)$ 는 사고 $\mathrm{i}$ 에 의한 손실액을 가리키며 $\mathrm{Fi}$ 는 사고 $\mathrm{i}$ 의 발생빈도이다. ALE는 정보보호 투자 적용 전후의 위험감소효과를 계산하는 것으로 요약하여 말할 수 있다.

$$
\begin{aligned}
& B=\triangle A L E=A L E_{\text {After }}-A L E_{\text {Before }} \\
& \text { 단, } B=\text { 편익 } \\
& A L E_{\text {After }}=\text { 정보보호투자 후 } A L E \\
& A L E_{\text {Before }}=\text { 정보보호투자 전 } A L E
\end{aligned}
$$

그러나 여기서 위험감소량을 측정하는 것은 다소 주관적 일 수 있다. 예를 들자면 개인정보 노출로 인한 손해배상금, 벌금 같은 부수적인 손실 그리고 회사 전체의 이미지, 브랜 드의 손상은 계량적으로 측정하는 데 있어서 어려운 문제점 이 있을 수 있다.

\section{2 순현재가치법}

일반적으로 정보보호투자는 의사결정 후 투자안이 시행될 때 기업의 현금유출이 발생하겠지만. 이로 인한 현금유입(또 는 비용절감)의 투자효과는 장기에 걸쳐 효과를 나타나게 된다. 이러한 현금유출과 유입의 단순비교는 화폐의 시간가 치를 고려하지 아니하였으므로, 올바른 의사결정이 아닌 것 이다. 그러므로 현재의 현금유출(투자비용)과 미래의 현금유 입의 시점 사이의 시간가치의 차이를 고려하여 시점을 일치 시켜서 계산하는 방법이 순현재가치법이다. 순현재가치 (NPV,Net Present Value)는 투자안으로부터 발생하는 현금 유입의 현재가치에서 현금유출의 현재가치를 뺀 값을 말한 다. 이를 수식으로 표현하면 다음과 같다.

$$
\begin{gathered}
\mathrm{NPV}=\text { 현금유입의 현재가치 }- \text { 현금유출의 현재가치 } \\
N P V=\sum_{t=1}^{n} \frac{C_{t}}{(1+k)^{t}}-C_{0} \\
C_{t}=t \text { 시점의 현금흐름 } \\
\left.C_{0}=\text { 현금유출(투자원금 }\right) \\
k=\text { 투자안의자본비용 (할인율) }
\end{gathered}
$$

정보보호투자에 있어서는 현금유입을 침해사고예방으로 인한 비용의 절감액으로 생각하면 될 것이고, 현금유출은 정 보보호 투자비용으로 생각하면 될 것이다. 예를 들어, 아래와 같은 투자안이 있을 경우 $\mathrm{NPV}$ 는 아래와 같이 계산된다.

$$
\begin{aligned}
& N P V(A)=\frac{500}{1.1}+\frac{800}{1.1^{2}}-1,000 \fallingdotseq 116 \text { 만원 }, \\
& N P V(B)=\frac{100}{1.1}+\frac{200}{1.1^{2}}-200 \fallingdotseq 56 \text { 만원 }
\end{aligned}
$$


Table 1. Two types of investment (Unit:Million Won)

\begin{tabular}{c|c|c}
\hline Period & Case A & Case B \\
\hline \hline 0 & -1000 & -200 \\
\hline 1 & 500 & 100 \\
\hline 2 & 800 & 200 \\
\hline \multicolumn{2}{|c}{ (Assumption: Cost of Capital $k=10 \%$ ) }
\end{tabular}

순현재가치법에서는 NPV가 0보다 크면 투자안이 채택된 다. 그러므로 투자예산이 충분한 경우에는 2 개의 투자안 모 두를 채택하게 되면 기업가치를 극대화하게 될 것이다. 그 러나 예산의 제약이 있는 경우는 예산제약에 맞는 적절한 선택을 하여야 할 것이다.

\section{3 내부수익률법}

내부수익률(IRR,Internal Rate of Return)은 투자안으로 부터 발생하는 현금유입의 현재가치(PV, present value)와 현금유출의 현재가치를 일치시켜 주는 할인율을 말한다. 또 한 현금 유입의 현재가치와 현금유출의 현재가치가 일치하 면 그 투자안의 NPV는 0이 되므로, 내부수익률은 투자안의 $\mathrm{NPV}$ 가 0이 되도록 하는 할인율이다, 따라서 다음의 식을 만족시키는 $I R R$ 이 내부수익률이다.

$$
\sum_{t=1}^{n} \frac{C_{t}}{(1+I R R)^{t}}-C_{0}=0 \text { 또는 } \sum_{t=1}^{n} \frac{C_{t}}{(1+I R R)^{t}}=C_{0}
$$

내부수익률법에서는 IRR이 투자안의 자본비용보다 크면 투자가치가 있는 것으로 평가하며, IRR이 큰 투자안을 보다 바람직한 투자안으로 평가된다. 그러므로 IRR은 투자의 결 정여부를 결정하는 수익률이라고 보면 될 것이다. 그러나 (1) 내용년수가 3 년 이상일 경우에는 내부수익률을 계산하기 가 어렵고 (2) 내부수익률의 계산에 있어서는 가치가산의 원 리가 성립하지 않으며 (3) 내부수익률은 절대적 금액보다는 수익률로서 의사결정하기 때문에 반드시 기업가치를 극대화 시켜 주는 투자안은 아니라는 문제점이 있다.

\section{3. 옵션 모형}

\section{1 옵션의 의의와 종류}

다음 절에서 실물옵션에 대해 살펴보기 이전에 실물옵션 의 기초가 되는 금융옵션을 통하여 옵션의 정의, 종류, 옵션 가격결정모형에 관해 살펴보고자 한다.

옵션(option)이란 미리 정해진 기간(만기)동안 정해진 가 격(행사가격)으로 특정자산(기초자산)을 사거나 팔수 있는 권리가 부여된 자산을 말한다. 즉, 옵션은 그 옵션의 보유자 에게 미래에 만기일이 도래하였을 경우 이에 상응하는 의무 없이 권리만을 제공하는 자산(asset)인 것이다. 만약, 투자를 실행하기 위한 적절히 좋은 환경이 발생한다면, 옵션의 보
유자는 보유옵션에 대한 행사가격(strike price)만큼 투자함 으로써 옵션을 실행할 수 있을 것이다.

옵션은 권리에 종류에 따라 콜옵션(Call Option)과 풋옵 션(Put Option)으로 구분된다. 또한 권리행사가 가능한 시기 에 따라 유럽형(European Option) 옵션과 미국형(American) 옵션으로 구분된다. 유럽형 옵션은 만기일에만 권리를 행사 할 수 있는 옵션을 말하며, 미국형 옵션은 만기일 이전에 언제든지 권리를 행사할 수 있는 옵션을 말한다[5].

\section{2 옵션가격결정모형(OPM, Option Pricing Model)}

정보보호투자와 같은 IT투자의 가치를 실물옵션에 의해 평가하기 위해서는 금융자산을 대상으로 하는 옵션가치 평 가방법론을 응용할 수 있으며, 일반적인 방법론으로는 연속 시간(continuous time)모형인 블랙-솔즈(Black-Sholes) 모형 과 이산시간(discrete time) 모형인 이항옵션가격결정모형 (BOPM,Binomial Options Pricing Model)및 몬테칼로 시뮬 레이션(Monte Carlo simulation) 등을 들 수 있다. 배당 (dividend)이 없는 단순한 경우를 가정하면 옵션가치를 평가 하기 위해 다섯 가지 입력변수가 요구되며, 이 입력변수는 행사가격(strike price : X), 주식의 현재가격(current stock price : S), 만기까지의 기간 (time to expiration : T), 무위 험 이자율(risk-free interest rate: $R_{f}$ ), 불확실성(미래 수익률 의 표준편차, uncertainty: $\sigma$ )이 된다.

또한 실물옵션 가치평가에서는 옵션 만기가 상대적으로 길기 때문에 투자비용과 같은 변수뿐만 아니라 불확실성과 같은 변수도 시간의 흐름에 따라 변하는 특성은 물론 여러 가지 옵션이 복합적으로 존재하는 특성을 갖게 된다. 따라 서 금융옵션 평가방법을 이용하여 실물옵션 가치를 올바르 게 평가하기 위해서는 금융옵션 평가방법론을 수정, 보완하 거나 확장할 필요가 있다.

이후부터는 실물옵션과 연계하여 옵션가치 평가방법론들 의 기초적인 개념 중에서 실물옵션평가를 위해 중요한 이론 적 기초가 되는 연속시간(continuous time)모형인 블랙-숄즈 (Black-Sholes)모형과 이산시간(discrete time) 모형인 이항 옵션가격결정모형(BOPM, Binomial Options Pricing Model) 에 대해 살펴보고자 한다.[6]

1) 블랙-숄즈(Black-Scholes)모형 [25〕

블랙-솔즈(F.Black and M.Scholes;1973)의 옵션가격 결정 모형은 다음의 가정에 기초하고 있다.

(1) 주가는 위너과정(Wiener process)을 따른다. 즉, 주가는 아주 미세한 시간 사이에서 연속적으로 변동하고, 로그정 규분포 $\log -$ normal distribution)를 이루며, 주식의 순간적 수익률은 일정한 기대치와 분산을 가진다.

(2) 주식시장과 옵션은 완전시장이며, 차익거래1)의 기회가 존재하지 않는다.

1) 수익과 위험이 같은 두자산이 시장에서 서로 다른 가격으로 거래되고 있을 경우 과대평가된 자산을 매각하고, 과소평가된 자산을 매입함으로써 추가자 금이나 위험을 전혀 부담하지 않고 두 자산의 가격차이 만큼 이익을 얻는 거래유형 
Table 2. Pricing Equation of European Call-Option (Black-Sholes Model)

$$
\begin{aligned}
& C=S \cdot N\left(d_{1}\right)-\frac{E}{e^{R_{f} T}} \cdot N\left(d_{2}\right) \\
& C=\text { Price of Call Option }, e=\text { Natural Logarithm }=2.71828 \ldots \\
& d 1=\frac{\ln \left(\frac{E}{S}\right)+\left(R_{f}+\frac{\sigma^{2}}{2}\right) T}{\sigma \cdot \sqrt{T}} \\
& E=\text { Exercise Price, } R_{f}=\text { RiskFree Rate } \\
& T=\text { Maturity } \\
& \ln (S / E)=\text { Natural Logarithmof }(S / E) \\
& d 2=\frac{\ln \left(\frac{S}{E}\right)+\left(R_{f}-\frac{\sigma^{2}}{2}\right) T}{\sigma \cdot \sqrt{T}} \\
& \sigma^{2}=\text { Annual Distribution of Stock Price - Earning Ration } \\
& N(d)=\text { Cumulative Probability of d (standardnormal deviate) } \\
& =d_{1}-\sigma \cdot \sqrt{T}
\end{aligned}
$$

(3) 주식과 옵션의 공매(short sale:空賣)2)에 제한이 없다.

(4) 연속 무위험 이자율 $\left(R_{f}\right)$ 은 일정하다.

블랙-솔즈의 모형에서도 뒤에서 다룰 이항옵션가격결정 모형에서와 동일한 논리로 옵션가격을 결정한다. 즉, 위 가 정하에서 주식과 옵션을 적절한 비율로 결합하여 투자하면 어떠한 순간 동안의 주가 변동위험을 완전히 헷지(hedge)할 수 있는 무위험 헷지 포트폴리오를 구성할 수 있으며, 시장 균형상태에서는 무위험헷지포트폴리오의 순간적인 수익률이 연속 무위험이자율과 같아야 한다는 미분방정식(differential equation)에 의하여 옵션가격을 결정한다.

그리고, 풋-콜 등가(put-call parity)3)에 위 유럽형 콜옵션 가격결정식을 대입하여 정리하면 풋옵션의 가격 결정식은 다음과 같다.

$$
P=\frac{E}{e^{R_{f} T}}\left[1-N\left(d_{2}\right)\right]-S\left[1-N\left(d_{1}\right)\right]
$$

블랙-솔즈의 옵션가격결정식을 보면, 옵션가격을 결정하 는 요인이 (1)기초자산의 현재가격(S), (2)기초자산 수익률의 분산 $\left(\sigma^{2}\right)$, (3) 행사가격 $(\mathrm{E})$, (4)만기(T), (5) 무위험이자율 $\left(R_{f}\right)$ 등 5 가지라는 것을 알 수 있다. 이 모형을 이용할 때는 기 초자산의 수익률의 분산을 정확하게 추정해 내는 것이 실무 상 가장 중요한 과제이다.

블랙-솔즈 모형을 이해하려면 $N\left(d_{1}\right)$ 과 $N\left(d_{2}\right)$ 의 경제적 의미를 알아야 한다. 먼저 $N\left(d_{1}\right)$ 의 의미를 파악하기 위해 블랙-솔즈에 의한 콜옵션가격식 Table 2 와 풋옵션 가격 결 정식을 현재주가(S)에 대하여 미분해 보면 다음과 같다.

$$
\frac{d C}{d S}=N\left(d_{1}\right), \frac{d P}{d S}=-\left[1-N\left(d_{1}\right)\right]
$$

2) 자산을 빌려서 매각하고, 정해진 시점에서 해당 자산을 매입하여 상환하는 것을 말한다.

3) 시장이 균형인 상태에서는 기초자산, 만기,행사가격이 모두 동일한 콜옵션 의 가격과 풋옵션의 가격이 일정한 관계를 갖는 것을 말하며, 식으로 나타 내면 아래와 같다. $(\mathrm{S}$ :현재주가, $\mathrm{P}$ 는 풋옵션 가격, $\mathrm{C}$ 는 콜옵션 가격, $\mathrm{PV}(\mathrm{E})$ 는 행사가격의 현재가치, + 는 매입, - 는 매도 $S+P-C=P V(E)$
즉, $N\left(d_{1}\right)$ 은 주가의 변화에 대한 콜옵션의 가격의 민감 도를 나타내며, $-\left[1-N\left(d_{1}\right)\right]$ 은 주가의 변화에 대한 풋 옵션 가격의 민감도를 나타내는 값이다.

한편 Table 2의 $N\left(d_{2}\right)$ 는 만기일에 콜옵션이 행사될 확 률을 의미하고, [식(7)]의 $\left[1-N\left(d_{2}\right)\right]$ 는 만기일에 풋옵션 이 행사될 확률을 의미한다. 따라서 블랙-솔즈 모형은 만기 일에 옵션을 행사하여 얻을 수 있는 이익을 옵션이 행사될 확률(불확실성)을 고려하여 현재가치(present value)로 평가 함으로써 옵션가격을 구하는 모형이다.

2) 이항옵션가격결정모형 (=이항모형, BOPM, Binomial Options Pricing Model)

이항옵션 가격결정 모형은 다음의 가정에 기초하고 있다. (1) 기초자산의 미래가격은 이항분포를 따른다. 기초자산의 가격은 매기간 일정률로 상승하거나 하락하는 두 가지 경 우만 발생하며, 상승확률 $(\mathrm{p})$ 와 하락확률(1-p)은 일정하다.

(2) 기초자산의 거래시장과 옵션시장은 완전시장이며, 차익 거래(arbitrage transaction)4)의 기회가 존재하지 않는다.

이항옵션가격결정모형의 가정의 의하면 1 기간 동안의 자 산 가격은 아래 Table 3 처럼 변동한다. 즉 현재의 자산가 격을 $S_{0}, 1$ 기간 동안의 (1+자산 가격 상승률)을 $\mathrm{u},(1$-자산 가격 하락률)을 $\mathrm{d}$ 라하면, 1 기간후의 자산 가격은 $\mathrm{q}$ 의 확률 로 $S_{o} u$ 가 되고, $(1-\mathrm{q})$ 의 확률로 $S_{0} d$ 가 된다.

Table 3. Asset Prices of Binomial Option Pricing Model (1 Period)

\begin{tabular}{c|c|c}
\hline \multirow{2}{*}{ Present } & \multicolumn{2}{|c}{ After 1 Period } \\
\hline \multirow{2}{*}{$S_{0}$} & $S_{o} u$ & Probability: q \\
\cline { 2 - 3 } & $S_{0} d$ & Probability: 1-q \\
\hline
\end{tabular}

4) 수익과 위험이 같은 두 자산이 시장에서 서로 다른 가격으로 거래되고 있 을 경우 과대평가된 자산을 매각하고, 과소평가된 자산을 매입함으로써 추 가자금이나 위험을 전혀 부담하지 않고 두 자산의 가격차이 만큼 이익을 얻는 거래유형 
그러면, 특정자산을 기초자산으로 하고, 만기가 1년, 행사 가격이 $\mathrm{E}$ 인 콜옵션(Call Option)의 가치는 아래의 <Table $4>$ 와 같이 변동한다. 즉, 자산 가격이 상승하면 만기일의 자 산 가격이 $S_{o} u$ 가 되므로 콜옵션(Call Option)의 가치 $\left(C_{u}\right)$ 는 $\operatorname{Max}\left[0, S_{0} u-E\right]$ 가 되고, 자산 가격이 하락하게 되면 만기일의 자산 가격이 $S_{0} d$ 가 되므로 콜옵션 $\left(C_{d}\right)$ 의 가치는 $\operatorname{Max}\left[0, S_{0} d-E\right]$ 가 된다.

Table 4. Volatility of Call Option Value (1 Period)

\begin{tabular}{c|c}
\hline Figure & After 1 Period \\
\hline \hline \multirow{3}{*}{$C_{0}$} & $\operatorname{Max}\left[0, S_{0} u-E\right]$ \\
\cline { 2 - 2 } & $\operatorname{Max}\left[0, S_{0} d-E\right]$ \\
\hline
\end{tabular}

기초 자산가격과 콜옵션가치가 이와 같이 변동할 경우, 자 산과 콜옵션을 적절할 비율로 결합하면 만기일에 자산가격의 변동과 관계없이 일정한 가치를 갖는 무위험 헷지 포트폴리 오(risk free hedge portfolio)5)를 구성할 수 있다. 이때 자산 1 개를 매입하고 $\mathrm{m}$ 개의 콜옵션을 매도하여 구성한 포트폴리 오를 가정해 보자. 이 포트폴리오의 현재가치는 $S_{0}-m C_{0}$ 가 되며 1 기간후의 가치는 Table 4처럼 변동할 것이다. 이 포트폴리오가 무위험헷지 포트폴리오가 되기 위해서는 자산 가격의 상승 및 하락과 관계없이 1 기간후의 자산 가치가 일 정해야 한다. 따라서 무위험헷지포트폴리오를 구성하기 위하 여 매도하여야하는 콜옵션의 수 $(\mathrm{m})$ 는 다음과 같이 구할 수 있는 데, 이를 헷지비율(hedge ratio)이라고 한다.

$u S_{0}-m C_{u}=d S_{0}-m C_{d}$ 에서 $m=\frac{u S_{0}-d S_{0}}{C_{u}-C_{d}}=\frac{S(u-d)}{C_{u}-C_{d}}$

시장이 균형인 상태에서는 위와 같이 구성한 무위험 헷지 포트폴리오의 수익률이 무위험이자율과 동일해야 한다. 따 라서 1 기간 동안의 무위험 이자율을 $R_{f}$ 라 하고, $\left(1+R_{f}\right)$ 를 $r$ 이라고 하면 다음의 관계가 성립한다.

$$
\left(S_{0}-m C_{0}\right) r=u S_{0}-m C_{u}=d S_{0}-m C_{d}
$$

이식을 $C_{0}$ 에 대해 정리하면 콜옵션의 균형가격은 아래 와 같이 구할 수 있다.

$$
C_{0}=\frac{S_{0}(r-u)+m C_{u}}{m \cdot r}
$$

5) 만기일에 자산가격의 변화와 관계없이 일정한 자산 가치를 갖는 포트폴리오
그리고 위 [식 10]에 $m=\frac{u S_{0}-d S_{0}}{C_{u}-C_{d}}$ 을 대입하여 정 리하면 다음과 같다.

$$
C_{0}=\frac{\left(\frac{r-d}{u-d}\right) C_{u}+\left(\frac{u-r}{u-d}\right) C_{d}}{r}
$$

여기서 $p=\frac{r-d}{u-d} \quad$ 라고 $\quad p$ 를 가정하면 $\frac{u-r}{u-d}=1-p$ 가 되므로, 다음과 같이 단순한 형태의 콜옵션 가격 결정식을 얻어낼 수 있다.

$$
C_{o}=\frac{p \cdot C_{u}+(1-p) C_{d}}{r}
$$

위의 [식 12]에서 $p$ 는 $0<p<1$ 이 되어 확률의 속성 을 갖는 값으로, 이를 헷지확률(hedge probability) 또는 위 험중립확률(risk-neutral probability) 이라고 한다.

헷지확률은 자산의 기대수익률이 무위험 이자율 $\left(R_{f}\right)$ 와 같아지도록 해주는 주가의 상승확률을 의미하는 값이며, 자 산 자체의 상승확률 $(\mathrm{q})$ 과는 다른 값이다. 즉 자산의 기대수 익률이 무위험이자율과 같아지도록 해주는 주가의 상승확률 을 $p$ 라고 하면

$$
p \cdot u+(1-p) d=r \rightarrow p=\frac{r-d}{u-d}
$$

가 되어 헷지확률과 동일해하며 콜옵션의 기대수익률이 무 위험 이자율과 같아지도록 해주는 자산의 상승확률과도 동 일함을 알 수 있다. 따라서 콜옵션의 균형가격은 헷지확률 을 자산의 상승확률로 해서 구한 만기일(1기간후)의 콜옵션 의 기대가치를 무위험 이자율로 할인한 현재가치가 된다.

\section{3) 몬테카를로 시뮬레이션(Monte Carlro Simulation>[12]}

몬테카를로 시뮬레이션은 난수를 사용해서 모형의 해를 구하는 기법이며, 모의확률실험이라고도 하는데, 실물에 의 한 실험이 불가능하거나 해석적 취급이 곤란한 경우에 유용 한 방법이다. 일반적으로 상당한 계산량을 필요로 하는데, 어떤 문제에 대해서도 적용할 수 있다는 장점이 있다.

시뮬레이션 구간이 $[0, T]$ 라 하면 시간경로를 $\mathrm{N}$ 등분하여 $\Delta t=T / N$ 로 놓고 시뮬레이션은 다음과 같은 과정을 거 쳐 산출된다.

$$
\begin{aligned}
& S_{t_{i}}=S_{t_{i-1}}+\mu S_{t_{i-1}} \Delta t+\sigma S_{t_{i-1}} e \sqrt{\Delta t}, \\
& t_{i}=i \Delta t, i=1,2, \ldots \ldots, N
\end{aligned}
$$

여기서 $S$ 는 기초자산 가격, $\mu$ 는 기대수익률, $e=2.71828$ 자연대수를 말한다. 
위의 식을 몬테카를로 시뮬레이션으로 실행시 기초변수는 기초 자산가격, 기대수익률, 변동성, 시간이다.

본 연구의 사례분석에서는 이를 위하여 Oracle社의 Crystal Ball 이라는 프로그램을 사용하였다.

\section{4. 실물 옵션}

\section{1 실물옵션 개요}

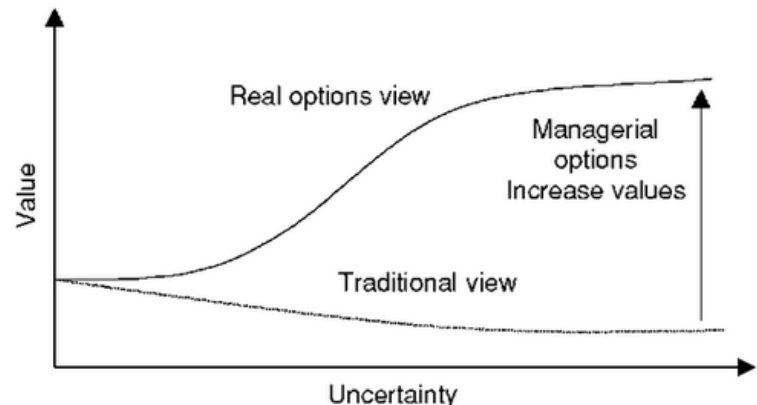

Fig. 1. Applied real options increase the value of your investment[28](Amram and Kulatilaka(1999))

실물옵션은 Myers(1977)에 의해 처음 제안되었으며[26] 금융옵션 개념에 기초하고 있다. 전통적 투자가치 평가기법 인 순현재가치법 또는 내부수익률법은 투자안의 가치에 영향 을 미치는 변수들이 투자시점에 이미 확정되어 있으며, 이는 미래에도 변동하지 않는다고 가정하고 있다. 따라서 순현재 가치법 투자가치평가시 이런 성장기회를 배제하여 투자가치 를 과소평가하는 반면에 실물옵션은 성장기회의 유연성 (flexibility)을 고려할 수 있는 장점을 갖게 된다. 이러한 유 연성을 고려함으로써 기업은 정보보호투자와 같은 불확실성 이 매우 큰 투자안에 대한 가치를 증가시킬 수 있는 것이 다.[(Fig. 1)참조] 이처럼 미래의 상황은 투자시점에서 예상하 던 것과는 달라질 수 있으며, 이로 인해 현재의 투자 결정을 변경해야 하는 경우가 있을 수도 있다. 만약 미래에 투자 결 정을 변경할 수 있는 기회가 있다면, 이는 일종의 앞에서 살 펴본 옵션과 유사한 성격을 갖는다 할 수 있을 것이다.

이러한 옵션은 실물투자 안에 내재되어 있는 옵션이라는 의미에서 실물옵션(Real Option)이라고 한다. 이처럼 대표적 인 형태로는 확장옵션( 또는 후속투자), 포기옵션( 또는 처분 기회), 연기옵션 (또는 시기 선택권) 등이 있다. 실물옵션이 내재되어 있는 투자안의 가치는 다음과 같이 순현재가치법에 의하여 평가된 투자안의 가치(실물옵션이 없을 때의 투자안 의 가치)에 실물옵션의 가치를 가산하여 구할 수 있다.

$N P V_{R}=N P V_{A}+R O V$,

단, $N P V_{R}=$ 실물옵션 적용시 투자안의 가치 $N P V_{A}=$ 실물옵션적용하기 전의 투자안의 가치 $R O V=$ 실물옵션의 가치
즉, 전통적 현재가치법 등에 의해 산출된 $\mathrm{NPV}$ 와 실물옵 션을 적용했을 때의 NPV의 차이라고 말할 수 있다.

\section{2 실물옵션으로서의 정보보호 투자}

\section{1) 정보보호 투자의 특성}

정보보호란 정보의 수집·가공·저장·검색·송신·수신 중에 정보의 훼손·변조·유출 등을 방지하기 위한 관리적·기술적 수단, 또는 그러한 수단으로 이루어지는 행위를 말하며, 일 반적으로 정보보호의 3대 기본 목표라 불리우는 아래 Table $5>$ 의 기밀성(Confidentiality), 무결성(Integrity), 가용성 (Availability)을 보장하기 위한 각종 수단을 말한다.

Table 5. The three basic goals of information security

\begin{tabular}{c|c}
\hline Items & \multicolumn{1}{c}{ Meaning } \\
\hline \hline Confidentiality & $\begin{array}{c}\text { Assurance that information is shared only } \\
\text { among authorised persons or organizations. }\end{array}$ \\
\hline Integrity & $\begin{array}{c}\text { Assurance that the information is authentic } \\
\text { and complete. Ensuring that information can } \\
\text { be relied upon to be sufficiently accurate for } \\
\text { its purpose }\end{array}$ \\
\hline Availability & $\begin{array}{c}\text { Assurance that the systems responsible for } \\
\text { delivering, storing and processing }\end{array}$ \\
information are accessible when needed, by \\
those who need them.
\end{tabular}

위와 같은 정보보호 목표들을 달성하기 위하여 식별 (Personal Identification), 인증(Authentication), 권한부여 (Authorization), 접근통제(Access Control), 부인방지 (non-repudiation) 와 같은 다양한 정보보호 기술들이 활용 되고 있으며, 이러한 정보보호기술을 활용하여 정보보호 목 표를 달성하기 위해서는 정보보호 관련 각종 $\mathrm{H} / \mathrm{W}, \mathrm{S} / \mathrm{W}$ 에 관련된 투자가 필요하다.

이러한 정보보호투자는 기계장치와 같은 생산설비처럼 미 래의 매출액의 증대에 직접적으로 영향을 미치는 투자안이 아니다. 또한 실제로 침해사고가 발생하기 전에는 기업으로 서는 불필요한 투자라고 여길 수 있는 개연성이 매우 높고 실제 침해사고가 발생하더라도 이로 인한 기업의 손실액을 측정하기도 용이하지 않다. 또한 정보보호 침해사고의 발생 을 예측한다는 것은 더더욱 어렵다. 이처럼 정보보호투자는 가시적 성과를 수치화하여 확인하기 매우 어렵기 때문에 투 자자안의 실행여부를 결정하기 매우 어려운 투자안이다. 이 러한 이유로 정보보호관련 투자효과를 분석하기가 매우 어 렵고 관련 연구에 애로점이 존재하는 것이다. 그러나 투자 안을 분석하기 위한 중요 변수들을 합리적인 방법으로 추정 한다면 보다 합리적으로 투자안을 분석할 수 있을 것이다. 예를 들어, 정보보호투자로 인한 편익을 침해사고로 인한 예상손실액의 절감액이라 하고 투자비용을 정보보호관련 
$\mathrm{H} / \mathrm{W}, \mathrm{S} / \mathrm{W}$ 구입을 위한 지출액이라고 한다면, 다른 실물자 산에 대한 투자안처럼 투자효과 분석이 가능할 것이다. 또 한 정보보호관련 투자편익은 침해사고의 발생확률과 관련되 어 있으므로 변동성(volatility)이 매우 높기 때문에 전통적 투자가치 분석 방법으로는 한계가 있으며, 유연성 (flexibility)을 반영할 수 있는 실물옵션 평가모형으로 분석 하는 것이 투자안의 분석에 보다 합리적이다.

\section{2) 실물옵션 평가모형 선택}

금융옵션의 경우 기초자산은 주식, 채권 또는 이자율 등 유가증권인데 반해 정보보호투자 관련 실물옵션은 네트워크 보안, 시스템 보안, 암호화, 인증, 보안관련 장비 또는 보안 컨설팅 관련 투자이다. 금융옵션이 금융시장에서 거래되는 유가증권과 관련되어 있기 때문에 가격, 수익률 등에 대한 데이터를 많이 축적하고 있어 옵션의 가치평가가 용이하다. 이에 반하여 실물옵션의 경우는 기초자산이 일반적으로 시 장에서 거래되지 않고 있다. 또한 현재까지 국내 기업의 정 보보호 투자효과에 관한 실증적인 연구가 진행된 사례는 거 의 없다. 따라서 가치평가에 필요한 데이터가 금융옵션에 비해 상대적으로 빈약하다. 또한, 정보보호 관련 투자기간은 금융옵션의 행사에 비하여 상대적으로 매우 길고 유럽형 보 다는 미국형일 가능성이 높다. 또한 실물옵션에서는 종종 배당개념의 기회비용손실이 발생하는 것이 매우 일반적이므 로 이 경우 블랙-숄즈 모형을 적용하는 것은 타당하지 않 다. 이러한 한계를 극복할 수 있는 방법론이 앞에서 설명한 이항옵션가격결정모형이다. 이모형은 가장 간단한 형태로 사용하기가 편리하고 주어진 한계 내에서 근사결과의 오차 가 그리 크지 않기 때문에 실물옵션의 분석도구로 적합하다 할 수 있다.

\section{3 실물옵션 분석을 위한 중요 변수의 결정}

정보보호투자에 있어서 실물옵션을 적용하기 위한 중요 변수를 Table 6에 나열하였다. 여기서 중요한 것은 다른 투
자안과 달리 정보보호의 편익은 현금유입의 성격보다는 현 금 유출액의 감소의 성격이 강하다는 것이고 가중평균 자본 비용을 산출하기 위해서는 정보보호 투자기업의 베타보다는 정보보호 산업과 같은 대용회사(proxy company)의 베타를 대용베타(proxy beta)로 사용하는 것이 정보보호투자의 위 험을 보다 잘 반영한다 할 수 있을 것이다. 아래 Table 6의 주요 항목의 자세한 설명은 아래 단원에서 다루기로 한다.

\section{1) 투자편익(현금유입)과 변동성}

정보보호투자의 현금흐름을 추정하기 위해서는 투자로 인 한 편익과 관련 비용을 추정하여 계량화하는 것이 첫 번째 단계일 것이다. 정보보호투자는 생산설비 투자와 같이 매출 액에 직접적인 기여를 한다기 보다는 투자로 인하여 기업 의 침해사고로 인한 예상되는 손실의 절감액을 편익 즉, 현 금유입으로 볼 수가 있다. 다만, 현금유입을 확정적 수치로 보지 않고 침해사고로 인하여 예상되는 손실의 절감액에 영 향을 주는 여러 변수들의 함수형태로 보며, 예상되는 손실 액의 절감액에 영향을 미치는 변수들로서는 침해사고 발생 확률, 발생건수, 피해금액 등 이들 변수들에 대하여 연도별 로 다양한 시나리오를 구성하여 현금흐름의 시나리오를 구 성하여야 한다. 그러나 현재 침해사고 관련 통계수치는 한 국인터넷 진흥원(KISA)에서 제공되는 침해사고 건수만 월 별로 제공될 뿐이므로 침해사고 피해금액 및 정보보호투자 로 인한 침해사고 예방액, 예방확률 등은 현실적으로 파악 하기 힘든 면이 존재한다. 그러므로, 아래 Table 7에서 세분 화된 피해종류별로 피해금액을 세분화한 뒤에 단원 2.1에서 언급한 ALE와 같은 연간 손실비용 총합과 발생빈도를 계산 하여 합산하여 위험 및 금액을 추정하여야 할 것이다.

위 분류 외에 기업의 이미지, 브랜드 가치 손상과 같은 파생적 비용을 고려할 수도 있으나, 파생적 비용 측정의 어 려움을 이유로 일반적으로 직접적 비용과 간접적 비용만을 고려하고 있는 실정이다. 그러므로 이 분야 관련된 다양한 이론 및 실증 연구가 진행된다면 침해사고 관련 비용측정과

Table 6. Primary financial variables for real option valuation

\begin{tabular}{|c|c|c|c|}
\hline \multicolumn{2}{|c|}{ Classification } & Primary Key Factor & Remark \\
\hline \multirow[b]{2}{*}{ Cash Flow } & $\begin{array}{c}\text { Cash Inflows } \\
\text { (=Reduction of losses) }\end{array}$ & $\begin{array}{l}\text { intrusion Accident }> \\
\text { - The amount of damage } \\
\text { - The probability of occurrence } \\
\text { - Prevention probability }\end{array}$ & $\begin{array}{l}\text { Simulation Using } \\
\text { statistics }\end{array}$ \\
\hline & $\begin{array}{l}\text { Cash Outflows } \\
\text { (=Investment Costs) }\end{array}$ & $\begin{array}{l}<\text { Information Security Industry }> \\
\text { Seles Growth Ratio } \\
\text { Operation Growth Ratio } \\
\text { - Income Tax Growth Ratio } \\
\text { - Operation Cash Flow Growth Ratio }\end{array}$ & \\
\hline \multirow{3}{*}{ Discount Ratio } & Risk-free interest rate & $\begin{array}{l}\text { Government Bonds interest rate } \\
\text { (Maturity 3 5 years) }\end{array}$ & \\
\hline & Cost of equity $\left(k_{e}\right)$ & $\beta$ of Related Industry Stock & proxy beta \\
\hline & Dept Capital Cost $\left(k_{d}\right)$ & $\begin{array}{l}\text { - Interest cost } \\
\text { - Liabilities Scale } \\
\end{array}$ & \\
\hline $\begin{array}{c}\text { Volatility of } \\
\text { Present Value }(\sigma)\end{array}$ & & & $\begin{array}{l}\text { - Historical Data, } \\
\text { - Expert Option. }\end{array}$ \\
\hline
\end{tabular}


Table 7. Damages element definitions and content[14]

\begin{tabular}{|c|c|c|c|}
\hline \multicolumn{2}{|c|}{ Damage elements } & Damage elements & Contents \\
\hline \multirow{2}{*}{$\begin{array}{l}\text { Direct } \\
\text { damage }\end{array}$} & Loss Prevention & $\begin{array}{l}\text { Loss of profits, revenue due to the loss } \\
\text { of availability of a system or network }\end{array}$ & $\begin{array}{l}\text { - Loss of sales opportunities } \\
\text { - Overtime pay }\end{array}$ \\
\hline & Cost of Recovery & Cost of recovery due to Incident & $\begin{array}{l}\text { - Cost of } \mathrm{H} / \mathrm{W} \text { replacement } \\
\text { - S/W reinstallation costs } \\
\text { - Reinstallation costs }\end{array}$ \\
\hline \multirow{2}{*}{$\begin{array}{l}\text { Indirect } \\
\text { damage }\end{array}$} & $\begin{array}{l}\text { Reduced Production } \\
\text { Efficiency }\end{array}$ & $\begin{array}{c}\text { Due to Incident, } \\
\text { Reduced Production Efficiency }\end{array}$ & $\begin{array}{l}\text { - Labor productivity decrease } \\
\text { - Work disability due to overload }\end{array}$ \\
\hline & Loss of Data & $\begin{array}{l}\text { Due to Incident, The value of the lost } \\
\text { data permanently }\end{array}$ & $\begin{array}{l}\text { - The value of the data } \\
\text { - Wage for Reproduction }\end{array}$ \\
\hline
\end{tabular}

Table 8. Information Security product sales Status[2]

(unit: Million Won)

\begin{tabular}{c|c|c|c|c|c|c}
\hline Classification & 2004 & 2005 & 2006 & 2007 & 2008 & 2009 \\
\hline \hline H/W, S/W & - & - & - & - & 589,850 & 757,130 \\
\hline Service & - & - & - & - & 149,029 & 173,324 \\
\hline TOTAL & $6,261,000$ & 680,700 & 705,200 & 722,040 & 738,879 & 930,454 \\
\hline Classification & 2010 & 2011 & 2012 & 2013 & 2014 & 2015 \\
\hline \hline H/W, S/W & 987,268 & $1,128,211$ & $1,206,809$ & $1,309,010$ & $1,411,154$ & $1,513,298$ \\
\hline Service & 250,505 & 294,967 & 323,000 & 360,034 & 397,068 & 434,102 \\
\hline TOTAL & $1,237,773$ & $1,423,178$ & $1,529,809$ & $1,669,044$ & $1,808,222$ & $1,947,400$ \\
\hline
\end{tabular}

*. Since 2011, Estimates Value

침해사고 비용 예방, 절감액을 통하여 정보보호 투자편익 측정에 보다 객관성을 확보할 수 있으리라 본다.

\section{2) 투자비용(현금유출)과 변동성}

정보보호 투자비용은 정보보호관련 $\mathrm{H} / \mathrm{W}, \mathrm{S} / \mathrm{W}$ 등에 대 한 투자금액일 것이므로, 편익에 비해 비용은 상대적으로 쉽게 산출이 가능할 것이다. 비록 Table 8 은 국내 전체 정 보보호제품의 매출액으로서 거시적 지표이지만, 이것은 곧 국내의 정보보호 제품의 수요현황 즉, 정보보호를 필요로 하는 수요기업의 투자 금액이 될 것이다. 그러므로 Table 8 에 나타난 수치의 변동성을 고려하여 정보보호 투자비용의 변동성을 추정하는 것도 합리적인 선택이 될 것이다.

예를 들어, 2012년 이후 2015년까지의 로그 성장률 $\left(\ln \left(S_{t} / S_{t-1}\right)\right.$, 단 $S_{t}$ 는 $t$ 기 매출액) 을 구하면 2013년 2015 년 동안 각각 $8,71 \%, 8.01 \%, 7.42 \%$ 의 성장률을 가지며 평균은 $8.05 \%$ 이고 표준편차는 $0.65 \%$ 라는 것을 계산할 수 있으며, 이것을 정보보호 수요기업의 투자비용의 변동성으로 가정할 수도 있다.

\section{3) 할인율의 추정}

정보보호관련 투자의 할인율을 추정할 경우에는 투자기업 의 가중평균자본비용인 $\mathrm{WACC}$ 를 사용하기 보다는 연관 산 업의 $\mathrm{WACC}$ 값을 사용하는 것이 투자안을 보다 정확히 평가 하는데 유용할 것이다. 왜냐하면, 정보보호투자는 관련 산업
의 주요 영업활동과 다른 체계적 위험을 가지는 것이 일반 적이기 때문이다. 자기자본비용 $\left(k_{e}\right)$ 은 일반적으로 자본자산 가격결정모형 $(\mathrm{CAPM})$ 을 활용하여 추정되어 진다.

$$
E\left(R_{i}\right)=R_{f}+\beta_{i}\left[E\left(R_{m}\right)-R_{f}\right]
$$

여기서, $R_{i}$ 는 개별주식 수익률, $R_{f}$ 는 무위험 이자율, $R_{m}$ 은 시장수익률을 나타낸다.

CAPM을 활용하여 할인율을 계산하기 위하여 "2012 국가 정보보호 백서"[2] 에서 파악된 국내 정보보호 관련업체 149 개 중 대형SI회사 4 개사 및 거래정지 2 개사를 제외한 12 개 사의 공시된 재무제표 및 주가자료를 통해 분석하였다. 대 형SI회사 4개사는 정보보호 매출보다는 SI관련 매출이 보다 클 것이라 예상되어 분석대상에서 제외하였다.

상기 Table 9의 정보보호관련 업체 12 개사의 최근 52 주 의 주가자료6)를 이용하여 종목별 시가총액에 의해 가중 평 균하여 계산한 베타는 1.13 으로 Table 10 과 같다. 베타가 1 보다 크므로 주식 투자자입장에서는 주가 민감도가 큰 공격 적 자신이지만, 다른 측면에서 해석한다면 불확실성이 매우 큰 정보보호투자의 성격을 반영한다고 볼 수 있으며, 이러 한 불확실성이 실물옵션분석방법 사용의 타당성을 높여준다 할 수 있겠다.

6) 52 Weeks: 2011.April 2012.April 
Table 9. Information Security Companies for Analysis

\begin{tabular}{c|c}
\hline Classification & Company Name \\
\hline \hline Analyed(12) & $\begin{array}{c}\text { NexG, Nitgen\&Company, SoftForum, Suprema, Secube, AnLab, IglooSecurity, } \\
\text { IniTec, EastSoft, FirsTec ,KCP,CrossCert }\end{array}$ \\
\hline Big Size SI Company(4) & Lotte Data Communication, Samsung SDS, S1, LG CNS \\
\hline suspension of trading (2) & Oullim Elses, Oullim Security \\
\hline Total & Total 18 Companies \\
\hline
\end{tabular}

Table 10. The estimated beta of Information Security Industry

\begin{tabular}{|c|c|c|c|c|c|}
\hline \multicolumn{2}{|c|}{ Classification } & \multirow{2}{*}{$\begin{array}{c}52 \text { Weeks } \beta \\
0.71\end{array}$} & \multirow{2}{*}{$\begin{array}{c}\text { Market } \\
\text { Capitalization } \\
\text { (Million Won) }\end{array}$} & \multirow{2}{*}{$\begin{array}{c}\text { Market } \\
\text { Capitalization } \\
\text { Ratio(A) }\end{array}$} & \multirow{2}{*}{$\begin{array}{c}\beta *(\mathrm{~A}) \\
0.000156017\end{array}$} \\
\hline 1 & NexG & & & & \\
\hline 2 & Nitgen\&Company & 0.81 & 275 & 0.000259353 & 0.000210076 \\
\hline 3 & SoftForum & 1.11 & 349 & 0.000329143 & 0.000365349 \\
\hline 4 & Suprema & 1.28 & 1,915 & 0.001806042 & 0.002311733 \\
\hline 5 & Secube & 1.11 & 326 & 0.000307451 & 0.000341271 \\
\hline 6 & AnLab & 1.03 & 10,895 & 0.010275103 & 0.010583356 \\
\hline 7 & IglooSecurity & 0.67 & 470 & 0.000443258 & 0.000296983 \\
\hline 8 & IniTec & 0.92 & 709 & 0.00066866 & 0.000615167 \\
\hline 9 & EastSoft & 2.14 & 1,401 & 0.001321287 & 0.002827554 \\
\hline 10 & FirsTec & 0.98 & 898 & 0.000846906 & 0.000829968 \\
\hline 11 & $\mathrm{KCP}$ & 1.04 & 1,029 & 0.000970453 & 0.001009271 \\
\hline 12 & CrossCert & 1.47 & 560 & 0.000528137 & 0.000776362 \\
\hline \multicolumn{2}{|r|}{ Total } & 13.27 & 19,060 & 0.017975536 & 0.020323107 \\
\hline \multicolumn{2}{|c|}{$\beta$ of Infomation Security Industry } & \multicolumn{4}{|c|}{1.13} \\
\hline
\end{tabular}

Table 11. The Debt Capital Cost of Information Security Industry

\begin{tabular}{c|c|c|c|c}
\hline Company Name & 2009 & 2010 & 2011 & Average \\
\hline \hline NexG & - & - & - & - \\
\hline Nitgen\&Company & 0.6667 & 0.0909 & 0.1176 & 0.2917 \\
\hline SoftForum & 0.1697 & 0.0267 & 0.2101 & 0.1355 \\
\hline Suprema & 0.0762 & 0.0099 & 0.0126 & 0.0329 \\
\hline Secube & 0.0230 & 0.0101 & 0.0040 & 0.0124 \\
\hline AnLab, & 0.0076 & 0.0243 & 0.0701 & 0.0340 \\
\hline IglooSecurity & 0.0121 & 0.0109 & 0.0054 & 0.0095 \\
\hline IniTec & 0.0607 & 0.0517 & 0.0406 & 0.0510 \\
\hline EastSoft & 0.0256 & 0.0090 & 0.0250 & 0.0199 \\
\hline FirsTec & 0.0100 & 0.0065 & 0.0069 & 0.0078 \\
\hline KCP & 0.0000 & 0.0059 & 0.0022 & 0.0027 \\
\hline CrossCert & 0.0000 & 0.0000 & 0.0018 & 0.0006 \\
\hline Total & 0.0456 & 0.0168 & 0.0345 & 0.0323 \\
\hline
\end{tabular}

무위험 수익률은 5년만기 국고채 수익률(최근 3.39\%)을 일반적으로 사용하며, 위험프리미엄은 일정기간의 KOSPI수 익률 또는 $\mathrm{KOSDAQ}$ 수익률과 무위험이자율 이용하여 국내 위험프리미엄을 추정한 후에 CAPM에 상기 투입변수를 대 입하여 자기자본비용 $\left(K_{e}\right)$ 를 추정할 수 있을 것이다.

타인자본 비용은 2009년부터 2011년 사이의 산술평균값을
통해 $3.23 \%$ 로 추정하였다. 타인자본비중 $(B)$ 과 자기자본비중 $(S)$ 은 각각 시가기준으로 산출하여 0.1515 와 0.8485 이며, 법인세율은 상기 12 개사의 최근 3 개년 평균 법인세율 $(t)$ $20.55 \%$ 를 추정하였다. 본 연구에서는 자기자본비용 $\left(k_{e}\right)$ 을 $13.7 \%$ 로 가정하였을 때 조달된 자기자본, 타인자본의 가중 평균비용은 약 $12 \%$ 로 추정되었다. 


$$
W A C C=k_{b}(1-t) \frac{B}{S+B}+k_{e} \frac{S}{S+B} \approx 12 \%
$$

여기서

$k_{b}=$ 타인자본비용,$k_{e}=$ 자기자본비용, $t=$ 법인세율 단, 부채 $(B)$ 비율 + 자기자본 $(S)$ 비율 $=1$

이처럼 계산된 할인율은 현금흐름의 $\mathrm{NPV}$ 를 계산하는 산 식에 분모로 사용되어 할인율이 상승하면 $\mathrm{NPV}$ 가 작아지게 되는 효과를 가져올 것이다. 그러므로, 할인율을 산정하는 것은 투자안의 실행여부를 결정하는 데에 매우 중요한 요소 이며 실물옵션 분석의 기초 단계가 된다.

\section{5. 사례 연구}

앞단원에서 실물옵션으로서의 정보보호투자와 관련되어 중요 변수를 산출할 경우 고려할 사항들을 살펴보았다. 이 번 단원에서는 앞서 언급한 바와 같이 정보보호투자관련 개 별기업의 통계자료가 미미한 관계로 중요변수가 앞장의 방 법론에 의해 산출되었다고 가정하고 가상의 정보보호 투자 사례를 들어 실제 실물옵션을 적용하는 방법론을 살펴보고 실물옵션 방법론의 유용성을 나타내고자 한다.
Table 12. The Assumption of Case Study

- benefits and costs follow a log-normal distribution

- The average revenue growth rate of $11.50 \%$

(Standard deviation of $10.48 \%$, a $\log$-normal distribution,

The rate of increase of the cost of an average of 5.00\% and a standard deviation $8.95 \%$ of the $\log$-normal distribution )

- Depreciation is fixed annually.

- Fixed the corporate tax rate to 20 percent annually.

- Discount Rate is $12 \%$.

- Risk-free interest rate is $5 \%$.

- Dividends are not taken into account.

\section{1 유연성이 없는 상황에서의 순현재가치 분석}

국내 대기업 $\mathrm{A}$ 사는 그룹본사 및 그룹계열사의 정보보안 침해사고 예방차원에서 보안관제센터를 건립하는 프로젝트 $\mathrm{X}$ 를 추진하고자 한다. 과거의 데이터 및 전문가의 의견과 시뮬레이션을 통하여 아래와 같은 가정을 수립하여 정보보 호 투자안에 대한 분석을 시도하였다. 전통적 투자분석 방 법인 순현재가치법으로 분석한 결과 프로젝트X의 현재가치 는 -84 백만원으로 투자가치가 없는 것으로 나타났다. 사회 전반적으로 침해사고 건수와 피해금액이 증가하는 상황에서

Table 13. The Evaluation of Present Value for Information Security Investment Projec (unit : million won)

\begin{tabular}{|c|c|c|c|c|c|c|c|c|c|}
\hline \multicolumn{3}{|c|}{ Classification } & $T=0$ & $T=1$ & $T=2$ & $T=3$ & $T=4$ & $T=5$ & $T=6$ \\
\hline \multirow{2}{*}{$\begin{array}{l}\text { The amount of direct } \\
\text { damage prevention }\end{array}$} & Loss Prevention & $1.00 \%$ & & 60 & 69 & 77 & 86 & 125 & \\
\hline & Cost of recovery & $15.00 \%$ & & 900 & 1,034 & 1,158 & 1,297 & 1,879 & \\
\hline \multirow{2}{*}{$\begin{array}{c}\text { The amount of indirect } \\
\text { damage prevention }\end{array}$} & $\begin{array}{r}\text { Reduced production } \\
\text { efficiency }\end{array}$ & $74.00 \%$ & & 4,440 & 5,102 & 5,713 & 6,398 & 9,271 & \\
\hline & Loss of data & $10.00 \%$ & & 600 & 689 & 772 & 865 & 1,253 & \\
\hline \multicolumn{2}{|c|}{ Revenue(=Benefit) } & $100.00 \%$ & & 6,000 & 6,895 & 7,720 & 8,646 & 12,529 & \\
\hline \multirow{5}{*}{$\begin{array}{c}\text { Infomation Security } \\
\mathrm{H} / \mathrm{W}\end{array}$} & Network Security & $35.00 \%$ & & 910 & 973 & 1,056 & 1,138 & 1,221 & \\
\hline & System Security & $20.00 \%$ & & 520 & 556 & 603 & 650 & 697 & \\
\hline & Spill prevention costs & $18.00 \%$ & & 468 & 501 & 543 & 585 & 628 & \\
\hline & $\begin{array}{l}\text { Encryption, } \\
\text { authentication costs }\end{array}$ & $7.00 \%$ & & 182 & 195 & 211 & 228 & 244 & \\
\hline & \begin{tabular}{|c|} 
Subtotal \\
\end{tabular} & $80.00 \%$ & & 2,080 & 2,359 & 3,004 & 2,909 & 3,852 & \\
\hline \multirow{4}{*}{$\begin{array}{c}\text { Information Security } \\
\text { Service }\end{array}$} & Security Management & $6.00 \%$ & & 156 & 167 & 181 & 195 & 209 & \\
\hline & Security Cunsulting & $10.00 \%$ & & 260 & 278 & 302 & 325 & 349 & \\
\hline & Etc. & $4.00 \%$ & & 104 & 111 & 121 & 130 & 139 & \\
\hline & & $20.00 \%$ & & 520 & 556 & 603 & 650 & 697 & \\
\hline \multicolumn{2}{|c|}{ Cost } & $100.00 \%$ & & 2,600 & 2,781 & 3,017 & 3,252 & 3,487 & \\
\hline \multicolumn{3}{|c|}{ EBITDA (Revenue - Cost) } & & 3,400 & 4,114 & 4,703 & 5,394 & 9,041 & \\
\hline \multicolumn{3}{|c|}{ Depreciation } & & 3,500 & 3,500 & 3,500 & 3,500 & 3,500 & \\
\hline \multicolumn{3}{|c|}{ EBIT ( EBIDA - Depreciation) } & & 100 & 614 & 1,203 & 1,894 & 5,541 & \\
\hline \multicolumn{3}{|c|}{ Income Tax (20\%) } & & - & 123 & 241 & 379 & 1,108 & \\
\hline \multicolumn{3}{|c|}{ Net Income } & & 100 & 491 & 963 & 1,515 & 4,433 & \\
\hline \multicolumn{3}{|c|}{ Depreciation } & & 3,500 & 3,500 & 3,500 & 3,500 & 3,500 & \\
\hline \multicolumn{3}{|c|}{ Initial Investment } & 35,000 & & & & & & \\
\hline \multicolumn{3}{|c|}{ Cash Flow } & $-35,000$ & 3,400 & 3,991 & 4,463 & 5,015 & 7,933 & \\
\hline \multicolumn{3}{|c|}{ Existence value } & & & & & & & 35,200 \\
\hline \multicolumn{3}{|c|}{ Discount rate } & $12.00 \%$ & & & & & & \\
\hline \multicolumn{3}{|c|}{ Present Value (PV) } & 34,916 & 35,706 & 35,999 & 35,856 & 35,144 & 31,429 & \\
\hline \multicolumn{3}{|c|}{ Net Present Value(NPV) } & 84 & & & & & & \\
\hline
\end{tabular}


$\mathrm{CEO}$ 는 프로젝트X가 성공적으로 침해사고를 예방효과가 있 다고 판단되어 추가로 프로젝트를 확장하게 된다면, 프로젝 트X의 현금흐름이 $20 \%$ 증가할 것으로 추산되는 반면에 8,000 백만원의 추가투자가 필요하다고 추산하였다. 또한 보 안관제센터를 유지하는 것을 포기하게 된다면 프로젝트X의 포기가치(salvage value)는 24,000백만원으로 추산된다. 따라 서 이기업의 $\mathrm{CFO}$ 는 이 프로젝트에 대한 실물옵션은 프로젝 트X의 확장을 행사할 수 있는 확장옵션과 포기에 따른 회 수를 결정할 수 있는 포기옵션을 감안하여 이러한 옵션들의 현재가치를 구해야 한다고 판단하였다.

이를 바탕으로 유연성이 없는 상황에서 순현재가치를 산 청하면 Table 13 과 같다. 즉 NPV가 - 84백만원으로 0보다 작게 산출되므로, 본 투자안은 기각되어야 할 것이다.

\section{2 유연성이 없는 상황에서의 순현재가치 분석}

\section{1) 현재가치의 변화율 계산}

가정에 주어진 수익과 편익의 변동성을 토대로 Monte Carlo 시뮬레이션을 수행하여 난수로 생성된 정보보호 수익 과 편익의 값들을 가지고 프로젝트X의 불확실성에 대한 값 을 알 수 있으며, 이것은 곧 프로젝트X의 변동성을 계산할 수 있다. 일반적으로 특정 변수의 변동성은 변화율의 표준 편차로 정의하므로 시뮬레이션된 현재가치 값들의 변화율의 표준편차를 구하면 된다. 가정에서 주어진 수익,비용의 평균 과 표준편차를 가지고 Crytal Ball 프로그램에 의하여 1,000 번의 시뮬레이션을 수행하면 (평균)수익률은 아래식과 같이 $11.58 \%$ 이다.

변화율 $11.58 \%$ 은 앞에서 설정한 할인율 $12 \%$ 와 거의 동 일함을 알 수 있다. 즉 평균적으로 약 $12 \%$ 의 가치변화는 할 인율 $12 \%$ 와 서로 일관성이 있음을 알 수 있다.
수익률 $($ rate of return $)=\ln \left(\frac{P V_{1}+C F_{1}}{E\left(P V_{0}\right)}\right)=11.58 \%$

여기서 $P V_{1}, C F_{1}$ 는 시뮬레이션에 의해 생성되는 투자안 의 수익과 비용의 다양한 변화값에 의해 생성되는 1 기 시점 의 현재가치와 현금흐름을 말한다. 그리고, $E\left(P V_{0}\right)$ 은 시뮬 레이션을 실행하기 전에 미리 계산된 0 기 즉 현재시점의 현 재가치의 기댓값이다.

\section{2) 이항모형의 적용}

앞에서 변동성을 계산하였으므로, 이를 바탕으로 이항모 형을 적용할 수 있다. 위의 Table 14, Table 15는 프로젝트 $\mathrm{X}$ 의 실물옵션 평가결과이다. 프로젝트의 변동성은 앞에서 시률레이션된 표준편차 $7.63 \%$ 를 사용하였다. 이를 기반으로 해서 현재가치의 이항경로의 확장을 위한 상승률 $(u)$ 과 하락 률 $(d)$ 은 다음과 같다.

$$
u=e^{0.0763}=1.07929 \quad d=e^{-0.0763}=0.92654
$$

이를 근거로 계산한 위험중립 상승확률 $p$ 는 가정에 주 어진 무위험 이자율 $\left(R_{f}\right)$ 를 이용하여 다음과 같이 구할 수 있다.

$$
p=\frac{e^{R_{f}}-d}{u-d}=\frac{e^{0.05}-0.92654}{1.07929-0.92654}=0.816592
$$

Table 14의 현재가치의 경로는 0기부터 시작하여 34,916 을 시작으로 해서 1 기에 상승의 경우 $34,916 \times$ $1.07929=37,684, \quad$ 하락의 경우 $34,916 \times 0.92654=$ 32,351 이며, 마찬가지로 2 기에는 37,684 가 상승하는 경

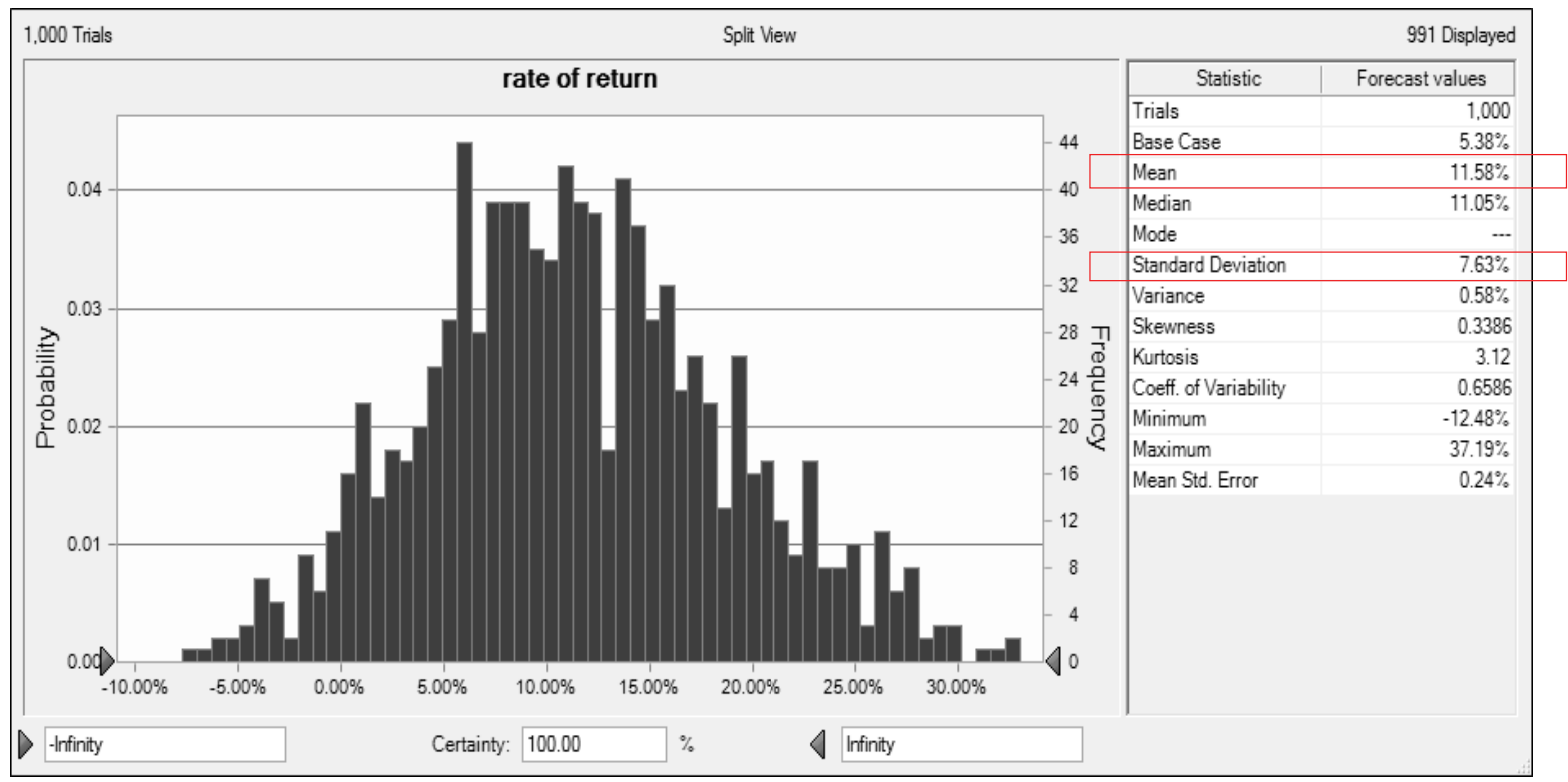

Fig. 2. The Rate of Return (Crystall Ball S/W Simulation) 
Table 14. The Path of Present Value (unit : million won)

\begin{tabular}{|c|c|c|c|c|c|c|}
\hline Period & $\mathrm{T}=0$ & $\mathrm{~T}=1$ & $\mathrm{~T}=2$ & $\mathrm{~T}=3$ & $\mathrm{~T}=4$ & $\mathrm{~T}=5$ \\
\hline & 34,916 & 37,684 & 40,672 & 3,897 & 47,377 & 51,133 \\
\hline & & 32,351 & 34,916 & 37,684 & 40,672 & 43,897 \\
\hline & & & 29,974 & 32,351 & 34,916 & 37,684 \\
\hline & & & & 27,772 & 29,974 & 32,351 \\
\hline & & & & & 25,732 & 27,772 \\
\hline & & & & & & 23,842 \\
\hline
\end{tabular}

우 40,672 , 하락하는 경우 34,916 로 계산되며, 이와 같은 방 법을 반복하여 만기시점에서의 현재가치 값들이 구해진다.

여기서 프로젝트X의 결정주체는 다음과 같은 조건을 행 사할 수 있음을 알 수 있다.

$$
\begin{aligned}
& M A X[51133,51133 \times 1.2-8000,22000] \\
& =M A X[51133,53360,22000]=53,360
\end{aligned}
$$

이 산식은 만기시점에서 프로젝트X의 가치가 51,133 인 경 우 (1) 그냥 프로젝트를 계속 진행하던지 (2) 프로젝트X에 추가비용 8,000 을 투자하여 현금흐름을 $20 \%$ 향상 시키던지 그리고 (3) 사업을 포기하여 포기가치 22,000 을 가지던지 등 세가지 옵션을 비교하여 최대값의 선택을 취한다는 것을 말 한다. Table 15에서 만기의 선택된 결과를 살펴보면 최대 53,360 그리고 최소 24,000 의 실물옵션 가치(ROV, Real Option Value)를 갖고 있음을 알 수 있다.

다음 단계는 Table 15에 계산된 실물옵션가치의 최대값 53,360 그리고 최소값 24,000 에서 후방 역계산을 하면 된다. 53,360 과 44,676 의 값을 가지고 위험중립 기댓값을 계산하여 무위험 이자율로 할인하여 계산한다.. 이 경우 산출된 값은 $e^{-0.05}[p \times 53,360+(1-p) \times 44,676]=49,243$ 이 된다. 이 값은 5 년차 시점에서 확장을 하지 아니하였을 경우 프로 젝트X의 실물옵션 가치이고 이를 확장을 하였을 경우와 포 기에 따른 포기가치와 비교하여 최대값을 선택하는 조건을 부여하여야 한다. 이는 다음과 같이 구할 수 있을 것이다.
$M A X[49243,49243 \times 1.2-8000,24000]$

$=M A X[49243,51091,22000]=51,091$

동일한 과정을 반복하여 1 년차 시점까지 계산할 경우 37,893 의 값을 얻을 수 있고, 여기서 초기 투자비용 35,000 을 차감할 경우 2,893 의 값이 나온다.

위 과정을 정리하면 확장가능성 및 포기가치의 계산 없 이, 즉 유연성을 고려하지 아니한 순현재가치법에 의하면 순현재가치는 -84 백만원 이었나 확장가능성 및 포기가치의 유연성을 포함하여 계산할 경우 $\mathrm{ROV}$ 순현재가치는 2,893 백 만원 임을 알수 있다. 따라서 유연성의 가치는 $2,893-(-84)=2,987$ (백만원) 로 평가할 수 있다. 즉, 경영의 유연성을 고려하지 않는 순현재가치법에 의하여 본 사례의 투자안을 평가하게 되면 부(-)의 현재가치가 산출되 어 투자안을 기각하여 기업가치 극대화라는 목표와는 상반 된 결과를 가져오지만, 확장과 포기라는 유연성을 고려하여 실물옵션분석기법을 활용하게 된다면 이처럼 다른 결과를 도출하게 되어 기업가치를 보다 증가시킬 수 있다는 것을 알 수 있다.

\section{6. 결 론}

기존 연구 결과에 의하면 수년전 국내 정보보호기술 투자 신규프로젝트에 실물옵션 기법을 사용하는 비율은 $0.19 \%$ 에 불과할 정도로 실물옵션을 기법을 국내에서 거의 활용하지

Table 15. The Path of Real Option Value

\begin{tabular}{|c|c|c|c|c|c|c|}
\hline Period & $\mathrm{T}=0$ & $\mathrm{~T}=1$ & $\mathrm{~T}=2$ & $\mathrm{~T}=3$ & $\mathrm{~T}=4$ & $\mathrm{~T}=5$ \\
\hline & 37,893 & 41,427 & 45,068 & 48,318 & 51,091 & 53,360 \\
\hline & & 32,754 & 35,435 & 38,353 & 41,533 & 44,676 \\
\hline & & & 29,975 & 32,351 & 34,916 & 37,684 \\
\hline & & & & 27,777 & 29,974 & 32,351 \\
\hline & & & & & 25,760 & 27,772 \\
\hline & & & & & & 24,000 \\
\hline
\end{tabular}
(unit : million won) 
않고 있음을 보여 주었다. 더욱이 조사과정에서 투자결정자 들이 실물옵션 기법에 대한 사전적인 지식의 부족으로 설문 에 응답하지 못한 사례도 있다고 한다. 또한 선진국과는 다 르게 우리기업의 투자결정자들이 일반적인 프로젝트 가치평 가기법을 사용하지 않고 투자를 결정하는 경우도 $25.71 \%$ 에 달했던 것으로 조사되기도 하였다. 그리고 실물옵션을 실무 상 적용하기 어려운 이유로 투자 변동성을 계산하기 어렵다 고 하는 것과 실물옵션에 대한 이해부족이라는 두 가지 이 유가 가장 큰 걸림돌로 작용한다는 응답결과를 보여주기도 하였다[6]. 현재도 그러한 상황이 크게 호전되지 않았으리라 고 추정되는 상황이다. 침해사고가 나날이 증가하는 오늘날 정보기술 신규프로젝트의 일부분인 정보보호투자의 신규프 로젝트에 있어서 실물옵션 기법을 거의 활용하지 않는다는 것을 간단히 유추해 볼 수 있는 것이다.

본 연구는 다른 일반적 투자안에 비하여 투자수익과 비용 의 금액산정 및 변동성을 측정하기 어려운 정보보호투자에 있어서 실물옵션을 적용하기 위한 중요변수들을 측정하는 경우 고려할 사항과 방법론을 제공함으로써 향후 기업이 미 래에 대한 불확실성이 큰 정보보호투자 의사결정에 있어서 실물옵션을 적용하기 위한 방법론을 제안하였으며, 이를 통 하여 실물옵션기법이 전통적 투자분석기법에 비하여 미래의 불확실성에 보다 유연하고 합리적인 결론을 도출해 낼 수 있다는 것을 알 수 있었다. 그러나 실물옵션 기법 역시 출 발점은 전통적 투자분석 방법의 $\mathrm{NPV}$ 에서 출발하기 때문에 $\mathrm{NPV}$ 추정의 한계점을 동일하게 가지고 있다. 또한 변동성 측정의 문제도 또 다른 한계점이다. 향후 정보보호투자와 관련된 다양한 통계치, 예를 들어 침해사고 피해금액, 발생 확률, 예방확률 등을 산정하기 위한 다양한 통계치와 이를 이용한 다양한 이론적 전개가 이루어 진다면 변동성 추정의 문제는 좀 더 객관적이고 합리적인 결과를 가져오리라 본 다. 이와 더불어 정보보호 투자에 대한 개별기업의 실증연 구와 더불어 실물옵션기법이 정보보호투자와 접목되어 발전 하리라 예상한다.

\section{참 고 문 헌}

[1] Korea Communication Commision, Ministry of Administration and Security, Ministry of Knowledge Economy, 2011 National Information Security White Papers, May, 2011.

[2] Korea Communication Commision, Ministry of Administration and Security, Ministry of Knowledge Economy, 2011 National Information Security White Papers, May, 2011.

[3] Seo Seung-Woo, Security Economics "Seoul Univ. Press", October, 2008.

[4] Jeong Byeong-Yeol, MicorEconomics Practice, "Segyeong Press", March, 2006.

[5] Kim Min-Hwan, Financial Management, "WooRi Management Acdemy”, Vol.4, December, 2005.
[6] Park Beom-Jo, The valuation of real options and uncertainties, "Sigma Press", July, 2009.

[7] Hong Dong-Pyo, Lee In-Hyung, Kim Kyung-Mi, The analysis of IT investments value using real options, "In-Sung Culture", December, 2001.

[8] Korea Information Security Agency(KISA), A Study on the Development of Internet security incident of calculating damages, 2006.

[9] Jeong Hyeong-Cheol And 6 other people, "Trend analysis of investment in information Security and Performance Analysis", National Information Society Agency, 2007.

[10] Kim Yeon-Dae, Study on methods of evaluating the venture corporation value using a Real Option Model, Yonsei University Graduate School, 2006.

[11] Han Jae-Jung, Study on methods of evaluating the corporation value using a real option model, Yonsei University Graduate School, 2005.

[12] Kim Sung-Min, Kwon Yong-Jang, Dynamic Valuation of the G7-HSR350X Using Real Option Model, Journal of Korean Society for RailWay, 2007.

[13] Lee Tae-Hee,Valuation of investment on HSDPA (High Speed Downlink Packet Access) service by real option approach ,Yonsei University Graduate School, 2007.

[14] Yu Chang-Seok, Valuation of Online Game Developers Using Real Options Analysis : the Case of Korea , Journal of Korea Game Society, October, 2011.

[15] Chae Seung-Hwan, The economic effects of the Private Information Security, Journal of Consumer Issues Research, Vol.33, April, 2008.

[16] Mun Sung-Ju, Kim Tae-Ho, A Study on the Real Option Approach to Apartment Reconstruction Projects Valuation, Journal of Financial Engineering Research, Vol.10, September, 2011.

[17] Kim Hye-Won, Jeong Seong-Hoon ,The Effect of Housing Price Flexibility on Housing Renewal Option Valuation , Journal of Daegu Gyeongbuk Research, Vol.10.1, December, 2011.

[18] Kim Tae-Sung, Research on the effects of investment in information Security, Journal of Korea Institute of Information Security \& Cryptology, Vol.17.4, August, 2007.

[19] Nam Sang-Hun/Lim Jong-In, Study on approaches for the economic evaluation of corporate investment in information Security, Journal of Korea Technology Innovation Society, 2005.

[20] KISA, "2011 Korea Information Security Industry Survey", December, 2011.

[21] KISA, Trends and Analysis Monthly Internet Incident, $2004.1^{\sim} 2012.5$ 
[23] Jingyue Li,Xiaomeng Su, "Making Cost Effective Security Decision with Real Option Thinking”, pp.2-3, 2007.

[24] Gordon,L.A. and M.P. Loeb, The Economics of Information Security Investment, June, 2002.

[25] Black,F. and M.Sholes, "The pricing of options and corporate liabilities”, Political Economy. Vol.81, June, 1973.

[26] Myers,S.C., "Determinant of corporate borrowing pricing", Journal of Futures and Option Research, 4, pp.1-21, November, 1977.

[27] Trigeorgis, L., "Real Options: An Overview", Schwartz and Trigeorgis, Real Options and Investment under Uncertainty, Cambridge:MIT Press, 2004.

[28] Amram,m. and N.Kulatilaka, "Real Option: Managing strategic investment in uncertain world, Boston, MA, Havard Business School Press, 1999.

[29] Olena Borissiouk and Janos Peli, "Real Option Approach to R\&D Project Valuation: Case Study at Serono Internationa S.A.”, University of Lausanne, 2002.

[30] Razib Hayat Khan, “ The Use of Rea Option Analysis(ROA) to assist in Security Solution Decisions", IJCSNS International Journal of Computer Science and Network Security, Vol.11, No.10, October, 2011.
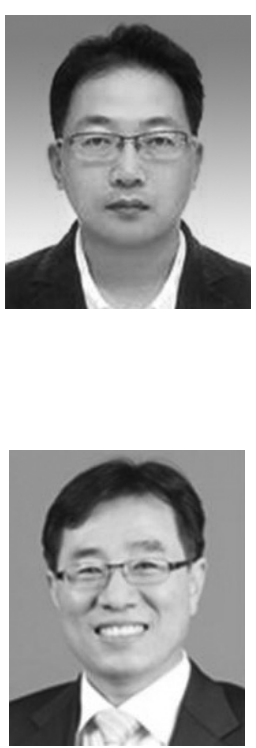

임 종 인

e-mail : jilim@korea.ac.kr 1980년 고려대학교 수학과 1982년 고려대학교 수학과(이학석사) 1986년 고려대학교 수학과(이학박사) 1986년 2001년 고려대학교 자연과학대학 정교수

2001년 2월 현 재 고려대학교 정보보호대학원 원장, 대검찰청 디지털 수사자문위원회 위원장, 금융보안연구원 보안전문기술위원회 위원장, 행정안전부 정책자문 위원회 위원, 방송통신 위원회 인터넷 협의회 운영 위원 등

관심분야: 정보법학, 디지털 포렌식, 개인정보보호, 전자정부보안, 융합기술보안 등 